"This is the peer reviewed version of the following article: ngew. Chem., Int. Ed. 2017, 56 (24), 6708-6710,, which has been published in final form at http://onlinelibrary.wiley.com/doi/10.1002/anie.201702188/abstract. This article may be used for non-commercial purposes in accordance with Wiley Terms and Conditions for Self-Archiving."

\title{
Forging C-C Bonds Through Decarbonylation of Aryl Ketones
}

\section{Rosie J. Somerville ${ }^{[a]}$ and Ruben Martin*[a],[b]}

As judged by the wealth of recent literature data, $\mathrm{C}-\mathrm{C}$ bondformation has evolved into a routine tool for building up molecular complexity. Indeed, $\mathrm{C}-\mathrm{C}$ bond-forming techniques play a prominent role in the preparation of fine chemicals and pharmaceuticals. However, the success of these methodologies has contributed to the perception that the field has reached a certain maturity. This observation is far from the truth, as the development of new and creative $\mathrm{C}-\mathrm{C}$ bond-forming reactions will make more chemical space accessible for organic chemists, thus improving the flexibility of synthetic design. ${ }^{[1]}$

classical C-C bond-cleavage methodologies

$$
\text { C } \frac{5}{\xi} \mathrm{C}+\underset{\text { path } \mathrm{a}}{\stackrel{\left[\mathrm{ML}_{\mathrm{n}}\right]}{\longrightarrow}} \mathrm{C}-\mathrm{C}+\mathrm{C}
$$

- C-C bond-cleavage via carbonyl decarbonylation 0<smiles>CC#CC(C)C</smiles>

Scheme 1. $\mathrm{C}-\mathrm{C}$ bond-cleavage followed by $\mathrm{C}-\mathrm{C}$ bond formation.

Prompted by the ubiquity of $\mathrm{C}-\mathrm{C}$ bond-linkages, chemists have been challenged to design sequential $\mathrm{C}-\mathrm{C}$ bondcleavage/C-C bond-formations (Scheme 1 , path a). ${ }^{[2]}$ While the release of ring strain makes strained rings susceptible to $\mathrm{C}-\mathrm{C}$ bond scission, chemists have also focused their attention on decarbonylative transformations of unstrained motifs, whereby $\mathrm{C}-\mathrm{C}$ cleavage is coupled with extrusion of carbon monoxide (CO). This allows a common functional group to become a handle for $\mathrm{C}-\mathrm{C}$ bond formation (Scheme 1, path $\mathrm{b}$ ). Although considerable success has been achieved with aldehydes, aroyl chlorides, thioesters, esters, and anhydrides, the use of simple ketones remains difficult due to the strength of the $\mathrm{C}-\mathrm{C}(\mathrm{O})$ bond and the affinity of $\mathrm{CO}$ for the metal center. ${ }^{[2]}$ Pioneering work by Teranishi, ${ }^{[3]}$ Murakami and Ito, ${ }^{[4]}$ however, demonstrated the feasibility of Rh-catalyzed $\mathrm{C}-\mathrm{C}(\mathrm{O})$ cleavage in strained rings or diketone precursors (Scheme 2, top). Murai, ${ }^{[5]} \mathrm{Shi}^{[6]}$ and Dong ${ }^{[7]}$ showed that the introduction of directing groups or the use of diynones could facilitate decarbonylation. However, the use of

[a] R. J. Somerville, Prof. R. Martin

Institute of Chemical Research of Catalonia (ICIQ)

The Barcelona Institute of Science and Technology

Av. Països Catalans 16, 43007, Tarragona (Spain)

E-mail: rmartinromo@iciq.es

[b] Prof. R. Martin

ICREA

Passeig Lluïs Companys, 23, 08010 Barcelona Spain simple biaryl ketones lacking nearby directing groups has received much less attention. The first report of simple biaryl ketone decarbonylation was reported by Brookhart and required stoichiometric amounts of particularly bulky cyclopentadienyl $\mathrm{Rh}(\mathrm{I})$ complexes. ${ }^{[8]}$ Despite the conceptual interest of these transformations, the typical use of expensive and noble Rh complexes may hinder the development of this field of expertise, thus reinforcing the need for a change in strategy.

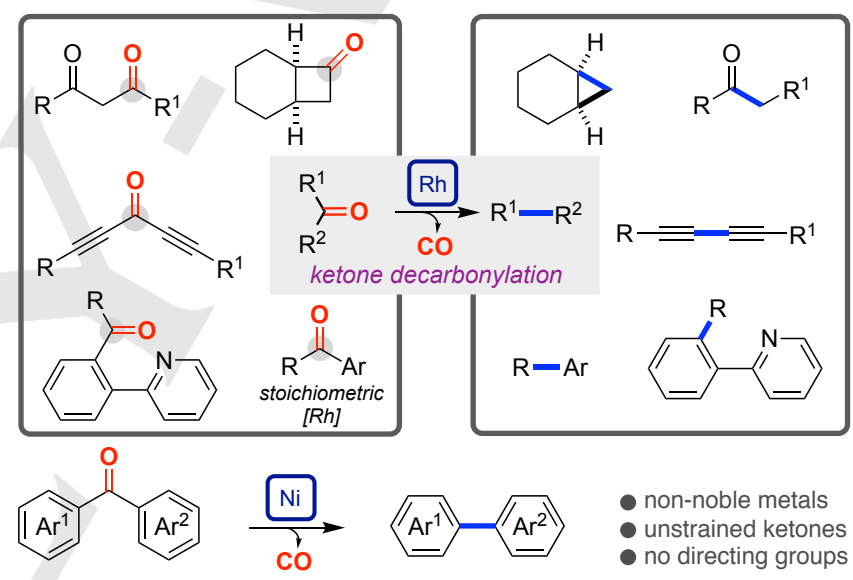

Scheme 2. Rh- and Ni-mediated ketone decarbonylation techniques

In recent years, nickel has received considerable attention in the cross-coupling arena due to its low price, ability to access multiple oxidation states and its extensive, yet reactive, organometallic chemistry. ${ }^{[9]}$ Indeed, nickel catalysts have been particularly suited to the activation of strong $\sigma$-bonds. ${ }^{[10]}$ Prompted by the nickel-mediated decarbonylation study reported by Ruhland (where proximal chelating groups were employed), ${ }^{[11]}$ Tobisu and Chatani have recently shown that nickel complexes can promote activation of the two $\mathrm{C}-\mathrm{C}(\mathrm{O})$ bonds of simple diaryl ketones and, after $\mathrm{CO}$ extrusion, form the corresponding biaryl product (Scheme 2, bottom pathway). ${ }^{[12]}$ Interestingly, although no reactivity was found for electron-rich phosphines - ligands often used for the Ni-catalyzed activation of strong $\sigma$-bonds ${ }^{[10]}$ - the desired decarbonylation was observed with stronger $\sigma$-donor $N$-heterocyclic carbene ligands. 


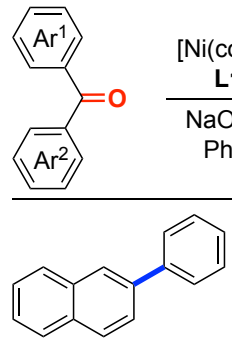

$59 \%$<smiles>c1ccc2c(c1)CCc1ccccc1-2</smiles>

$52 \%$

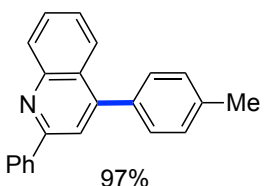

Me
$\left.\mathrm{Ni}(\operatorname{cod})_{2}\right]$ (1 equiv) L1 (1 equiv)

equiv)<smiles>CN(C)c1ccc(-c2ccc3ccccc3c2)cc1</smiles>

$52 \%$<smiles>Cc1ccccc1-c1ccc2ccccc2c1</smiles><smiles>Cc1cc(C)cc(-c2cnc3ccccc3c2)c1</smiles>

$92 \%$

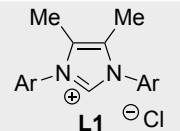

$\mathrm{Ar}=1,3,5-\mathrm{Me}_{3} \mathrm{C}_{6} \mathrm{H}_{2}$

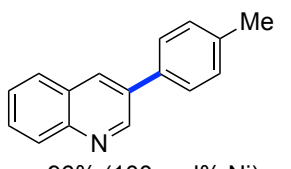

$96 \%(100 \mathrm{~mol} \% \mathrm{Ni})$

64\% (20 mol\% Ni)<smiles>FC(F)(F)c1ccc(-c2ccc3ccccc3c2)cc1</smiles>

$53 \%$

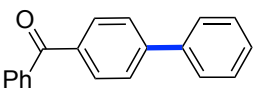

$64 \%$
Scheme 3. Selected examples of the nickel-mediated ketone decarbonylation.

The generality of the transformation was briefly investigated, and a variety of diaryl ketones possessing different substitution patterns participated well in the reaction (Scheme 3) ${ }^{[12]}$ Notably, the presence of ortho-substituents did not hinder the reaction. The reaction generally required stoichiometric amounts of both $\left[\mathrm{Ni}(\operatorname{cod})_{2}\right]$ and $\mathbf{L} \mathbf{1}$, along with high temperatures $\left(160^{\circ} \mathrm{C}\right)$. Note, however, that a substrate with a 3-substituted quinolinyl motif allowed for the use of $20 \mathrm{~mol} \% \mathrm{Ni}(\operatorname{cod})_{2}$, with a $64 \%$ yield of the biaryl product being obtained. Although full interpretation of these results awaits further investigations, the turnover observed with this substrate certainly paves the way for future directions of this transformation. The chemoselectivity issues of the reaction could not fully be assessed, probably due to the high temperatures required for effecting the transformation. Although beyond the scope of this reaction, a successful extension to aryl alkyl ketones would provide an intriguing new entry to alkylated arenes without the need for directing groups. ${ }^{[5]}$ "push-pull" effects in $\mathrm{C}-\mathrm{C}$ bond-cleavage<smiles>[R]c1ccc(C(=O)c2ccc([R])cc2)cc1</smiles>

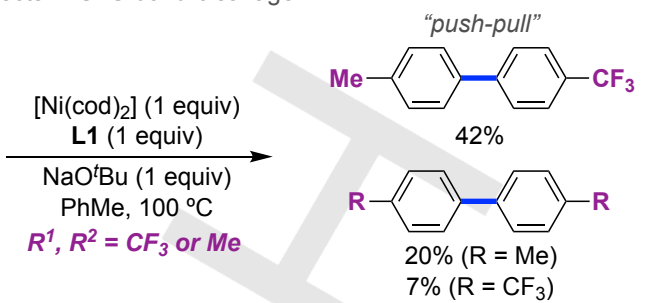

proposed mechanistic rationale<smiles>O=C(c1ccccc1)c1ccccc1</smiles>
C-C cleavage $\overrightarrow{\mathrm{Ni}(0)(\mathrm{L} 1)}$<smiles>[CH]N(C(=O)OCC)c1ccccc1</smiles><smiles>O=C1[NH+](c2ccccc2)C12CCCCC21CCCCC1</smiles>
e-poor $\mathrm{Ar}^{1}$
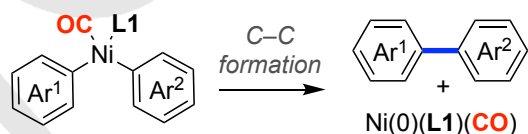

Scheme 4. "Push-pull" effects and mechanistic rationale.

Crossover experiments with substrates bearing electronicallydifferentiated arenes provided compelling evidence for an intramolecular mechanism. ${ }^{[12]}$ Mechanistic understanding of the transformation, however, remains elusive at this time. The authors proposed a scenario involving an initial oxidative addition into one of the $\mathrm{C}-\mathrm{C}(\mathrm{O})$ bonds, followed by decarbonylation and a final reductive elimination (Scheme 4 , bottom). In order to obtain empirical evidence for this pathway, the authors speculated that whereas oxidative addition should occur at the most electron-poor $\mathrm{C}-\mathrm{C}(\mathrm{O})$ bond adjacent to an electron-poor arene, the subsequent $\mathrm{C}-\mathrm{C}$ cleavage should be favored by a more electron-rich arene moiety. This hypothesis turned out to be correct, with diaryl ketones containing both electron-withdrawing and electron-donating groups providing higher conversions than regular arenes possessing either electron-withdrawing or electron-rich groups (Scheme 4, top). Although these experiments certainly shed light on the different behavior exerted by electronically-differentiated arenes, the inclusion of a computational study and physical organic investigations would have been necessary to fully explain the elementary steps of this reaction. Given the ability of low-valent $\mathrm{Ni}(0)$ complexes possessing electron-rich ligands to bind to carbonyl compounds in a $\eta^{2}$-fashion, ${ }^{[13]}$ we speculate that the formation of such a complex would precede and facilitate the a priori uphill $\mathrm{C}-\mathrm{C}(\mathrm{O})$ bond-cleavage.

According to the postulated mechanism, a $\left[\mathrm{Ni}(0)(\mathbf{L} \mathbf{1})(\mathrm{CO})_{n}\right]$ complex is generated during the reaction. Although the authors did not report the synthesis of such a complex, indirect evidence for its formation came from an IR spectrum of the crude reaction mixture that revealed a distinctive stretching frequency at 1980 $\mathrm{cm}^{-1} \cdot{ }^{[12]}$ As the affinity of low-valent metal complexes for CO can make turnover problematic, we believe that future research should be focused on overcoming this drawback. Indeed, the release of $\mathrm{CO}$ from a low-valent $\mathrm{Ni}(0)$ species is certainly not impossible, as demonstrated by recent reports of nickelcatalyzed decarbonylative coupling reactions of aryl esters. ${ }^{[14]}$ Although the reasons behind successful catalyst turnover were 
not investigated in every case, techniques used to prevent deactivation of the $\mathrm{Ni}$ catalyst include carrying out the reaction under a flow of $\mathrm{N}_{2}{ }^{[14 \mathrm{~b}]}$ and the use of high temperatures. ${ }^{[14 \mathrm{c}]}$ Alternatively, one could envision trapping the extruded $\mathrm{CO}$ in a complementary side reaction, a technique that has already been employed in aldehyde carbonylation. ${ }^{[15]}$ In any case, we are certainly confident that the recent protocol discovered by Tobisu and Chatani ${ }^{12]}$ could provide a significant technological push towards a more prolific use of abundant first-row transition metals in decarbonylation strategies. We anticipate that a deep understanding of the mechanism obtained by combining theoretical and experimental techniques will set the basis for future advances in this field.

In conclusion, electron-rich $\mathrm{Ni}(0)$ complexes have been shown to be suitable for effecting a rather elusive ketone decarbonylation, and thus complement existing methodologies based on noble Rh complexes. This finding establishes an important proof of concept that showcases the unique ability of nickel species to trigger interesting bond disconnections, and further reinforces the potential of using decarbonylation as a tool for organic synthesis. We certainly expect continued growth in this rather unexplored field of expertise.

\section{Acknowledgements}

We thank ICIQ, MINECO (CTQ2015-65496-R and Severo Ochoa Excellence Accreditation 2014-2018, SEV-2013-0319) for support. R. J. Somerville thanks the "La Caixa" Severo Ochoa program for a predoctoral fellowship.

Keywords: nickel $\cdot \mathrm{C}-\mathrm{C}$ cleavage $\cdot$ decarbonylation $\cdot$ crosscoupling $\cdot \mathrm{C}-\mathrm{C}$ bond formation

[1] In Metal-Catalyzed Cross-Coupling Reactions, 2nd ed. (Eds. A. De Meijere, F. Diederich), Wiley-VCH, Weinheim, 2004
[2] For selected reviews: a) L. Souillart, N. Cramer, Chem. Rev. 2015, 115, 9410-9464; b) Cleavage of carbon-carbon single bonds by transition metals, (Eds. M. Murakami, N. Chatani), Wiley-VCH, Weinheim, 2015; c) F. Chen, T. Wang, N. Jiao, Chem. Rev. 2014, 114, 8613-8661

[3] K. Kaneda, H. Azuma, M. Wayaku, S. Teranishi, Chem. Lett. 1974, 3, 215-216.

[4] M. Murakami, H. Amii, Y. Ito, Nature 1994, 370, 540-541.

[5] N. Chatani, Y. le, F. Kakiuchi, S. Murai, J. Am. Chem. Soc. 1999, 121, 8645-8646.

[6] Z.-Q. Lei, H. Li, Y. Li, X.-S. Zhang, K. Chen, X. Wang, J. Sun, Z.-J. Shi, Angew. Chem. Int. Ed. 2012, 51, 2690-2694; Angew. Chem. 2012, 124, 2744-2748.

[7] A. Dermenci, R. E. Whittaker, Y. Gao, F. A. Cruz, Z.-X. Yu, G. Dong, Chem. Sci. 2015, 6, 3201-3210

[8] O. Daugulis, M. Brookhart, Organometallics 2004, 23, 527-534.

[9] a) V. P. Ananikov, ACS Catal. 2015, 5, 1964-1971; b) S. Z. Tasker, E. A. Standley, T. F. Jamison, Nature 2014, 509, 299-309.

[10] a) A. N. Desnoyer, J. A. Love, Chem. Soc. Rev. 2017, 46, 197-238; b) M. Tobisu, N. Chatani, Acc. Chem. Res. 2015, 48, 1717-1726; c) J. Cornella, C. Zarate, R. Martin, Chem. Soc. Rev. 2014, 43, 8081-8097

[11] K. Ruhland, A. Obenhuber, S. D. Hoffmann, Organometallics 2008, 27, 3482-3495.

[12] T. Morioka, A. Nishizawa, T. Furukawa, M. Tobisu, N. Chatani, J. Am. Chem. Soc. 2017, 139, 1416-1419.

[13] a) J. Cornella, E. Gómez-Bengoa, R. Martin, J. Am. Chem. Soc. 2013, 135, 1997-2009; b) M. Ohashi, H. Saijo, T. Arai, S. Ogoshi, Organometallics 2010, 29, 6534-6540; c) T. Tamaki, M. Nagata, M. Ohashi, S. Ogoshi, Chem. Eur. -J. 2009, 15, 10083-10091.

[14] Selected references: a) L. Guo, A. Chatupheeraphat, M. Rueping, Angew. Chem. Int. Ed. 2016, 55, 11810-11813; Angew. Chem. 2016, 128, 11989-11992; b) N. A. LaBerge, J. A. Love, Eur. J. Org. Chem. 2015, 2015, 5546-5553; c) K. Amaike, K. Muto, J. Yamaguchi, K. Itami J. Am. Chem. Soc. 2012, 134, 13573-13576.

[15] Selected references: a) T. C. Fessard, S. P. Andrews, H. Motoyoshi, E. M. Carreira, Angew. Chem., Int. Ed. 2007, 46, 9331-9334; Angew. Chem. 2007, 119, 9492-9495; b) F. Y. Kwong, H. W. Lee, W. H. Lam, L. Qiu, A. S. C. Chan, Tetrahedron: Asymmetry 2006, 17, 1238-1252 


\section{HIGHLIGHT}
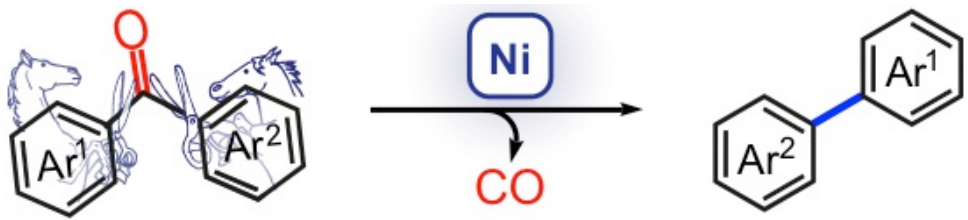

Rosie J. Somerville, Ruben Martin*

Page No. - Page No.

Forging C-C Bonds Through

Decarbonylation of Aryl Ketones

Nickel's ability to cleave strong $\sigma$-bonds is again in the spotlight after a recent report that demonstrates the feasibility of nickel complexes to promote decarbonylation of diaryl ketones. This transformation involves the cleavage of two strong $\mathrm{C}-\mathrm{C}(\mathrm{O})$ bonds and avoids the use of noble metals, hence reinforcing the potential of decarbonylation as a technique for forging $\mathrm{C}-\mathrm{C}$ bonds. 